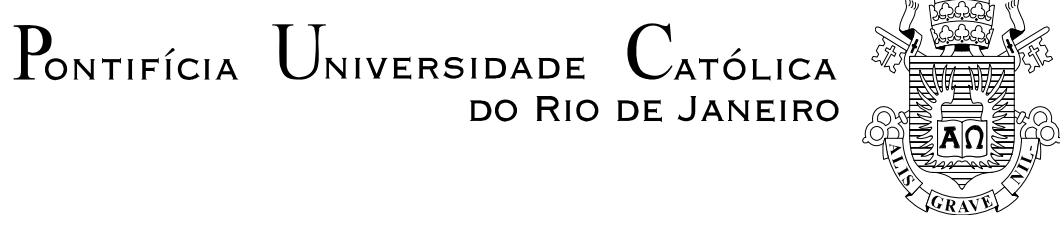

Paula Almada Horta Deiró

Bulimia nervosa e família: Evolução e tratamento da doença

Dissertação de Mestrado

Dissertação apresentada como requisito parcial para obtenção do grau de Mestre pelo Programa de Pósgraduação em Psicologia do Departamento de Psicologia da PUC-Rio.

Orientadora: Profa. Andrea Seixas Magalhães

Rio de Janeiro

Março de 2011 


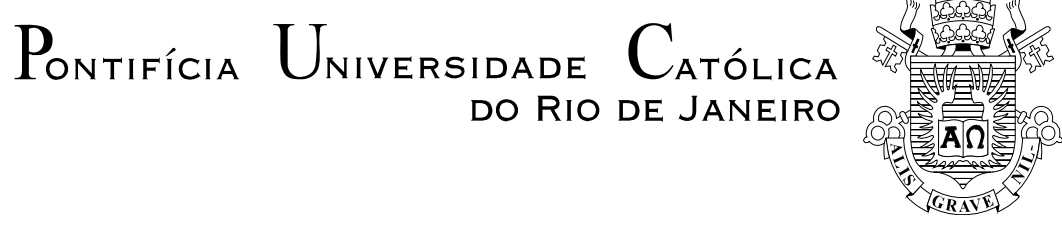

Paula Almada Horta Deiró

\section{Bulimia nervosa e família: Evolução e tratamento da doença}

Dissertação apresentada como requisito parcial para obtenção do grau de Mestre pelo Programa de PósGraduação em Psicologia Clínica do Departamento de Psicologia do Centro de Teologia e Ciências Humanas da PUC-Rio. Aprovada pela Comissão Examinadora abaixo assinada.

Profa. Andrea Seixas Magalhães

Orientadora

Departamento de Psicologia - PUC-Rio

Profa. Terezinha Feres Carneiro Departamento de Psicologia - PUC-Rio

Profa. Tatiana Moya Associação Brasileira de Psiquiatria - ABP

Profa. Denise Berruezo Portinari Coordenadora Setorial de Pós-Graduação

e Pesquisa do Centro de Teologia e Ciências Humanas - PUC-Rio

Rio de Janeiro, /2011. 
Todos os direitos reservados. É proibida a reprodução total ou parcial do trabalho sem autorização da universidade, da autora e da orientadora.

\section{Paula Almada Horta Deiró}

Graduou-se em Psicologia em Janeiro de 2005. Fez curso de Formação em Gestalt-terapia. É membro de uma equipe multidisciplinar que trabalha com transtornos alimentares e obesidade desde 2005. Atua em consultório particular desde 2005 .

Ficha Catalográfica

Deiró, Paula Almada Horta

Bulimia nervosa e família: evolução e tratamento da doença / Paula Almada Horta Deiró; orientadora: Andrea Seixas Magalhães. - 2011.

$90 \mathrm{f.} ; 30 \mathrm{~cm}$

Dissertação (mestrado) - Pontifícia Universidade Católica do Rio de Janeiro, Departamento de Psicologia, 2011.

Inclui bibliografia

1. Psicologia - Teses. 2. Bulimia nervosa. 3. Transtorno alimentar. 4. Família. 5. Psicoterapia. I. Magalhães, Andrea Seixas. II. Pontifícia Universidade Católica do Rio de Janeiro. Departamento de Psicologia. III. Título.

CDD: 150 
À minha família, que me ensinou o valor de relações baseadas em amor e respeito. 


\section{Agradecimentos}

À minha orientadora, Andrea Seixas Magalhães, por ter me acompanhado de perto durante este percurso. Sua delicadeza me inspirou e me motivou em muitos momentos.

Aos profissionais com quem trabalhei e trabalho, especialmente os da equipe Nuttra, com quem aprendi e aprendo muito sobre a teoria e a prática clínica dos transtornos alimentares.

Ao meu marido, João, pelo amor, paciência e ajuda na correção deste trabalho.

Aos meus pais, Kátia e Roberto, pelo amor incondicional, pela constante presença e estímulo no meu percurso acadêmico.

Aos meus irmãos, Pedro e Rodrigo, por acreditarem sempre em mim.

À Luiza, por tudo que já fez e faz por mim, pelo amor tão especial.

Ao meu querido primo Yuri, em memória, por me ensinar que um sorriso e um abraço tornam a nossa vida mais plena.

A toda a minha família pela motivação e carinho de sempre.

Aos meus amigos pela compreensão de minha ausência em algumas situações e pelos momentos de distração e diversão durante este percurso.

À minha querida amiga Carol Cunto pela sua amizade muito especial, por seu apoio ímpar e pela sua ajuda na correção e melhoria deste trabalho.

Às minhas amigas Marina Agarez, Elisa Guahyba e Solange Frid, pelo companheirismo durante esses dois anos de mestrado e pelo apoio nos momentos mais complicados, além daqueles de descontração e amizade.

Às minhas sócias do Cinco Espaço Psicoterapêutico, Christine, Fernanda, Luiza e Sheila, pela compreensão, pelo carinho e pelo apoio em todos os momentos.

Aos meus clientes, pela disponibilidade e confiança.

Aos entrevistados, pela generosidade e coragem.

À Tatiana Moya, pelo companheirismo e troca nos atendimentos e por aceitar participar da banca examinadora. 
À Terezinha Féres-Carneiro, pelas aulas e reflexões durante o mestrado e por fazer parte da banca examinadora.

Aos professores e funcionários do Departamento da Pós-Graduação de Psicologia, pelo apoio.

À PUC-Rio, pela excelente pós-graduação. 


\section{Resumo}

Deiró, Paula Almada Horta; Magalhães, Andrea Seixas (Orientadora). Bulimia nervosa e família: evolução e tratamento da doença. Rio de Janeiro, 2011. 90p. Dissertação de Mestrado - Departamento de Psicologia, Pontifícia Universidade Católica do Rio de Janeiro.

Este estudo tem como objetivo investigar, a partir do relato de pacientes com diagnóstico de bulimia nervosa, o papel da família na evolução e no tratamento deste transtorno alimentar. Para tanto, foi realizada uma pesquisa qualitativa, com seis mulheres acometidas por bulimia nervosa, com idades entre 19 e 32 anos, pertencentes às camadas médias e altas da população carioca. Todas as entrevistadas estavam em tratamento com equipes especializadas em transtornos alimentares. Inicialmente, foi realizado um estudo teórico a respeito das características da bulimia nervosa e das famílias com um membro com transtorno alimentar, incluindo a evolução do tratamento familiar. Esse estudo fundamentou a análise das entrevistas e, posteriormente, a elaboração de seis categorias. Por meio da análise dos relatos das entrevistadas, evidenciou-se que a maioria delas associou diretamente os seus sintomas alimentares a questões familiares, apontando para situações específicas ou recorrentes, nas quais buscaram refúgio e apoio na comida. A partir da análise dos relatos das entrevistadas, concluiu-se ser de extrema importância o envolvimento da família no tratamento da bulimia nervosa para que as questões relacionadas à dinâmica disfuncional desse sistema sejam elaboradas e, com isso, a paciente possa apresentar melhoras em seus sintomas.

\section{Palavras-chave}

Bulimia nervosa; transtorno alimentar; família, psicoterapia. 


\section{Abstract}

Deiró, Paula Almada Horta; Magalhães, Andrea Seixas (Advisor). Bulimia nervosa and family: development and treatment of the disease. Rio de Janeiro, 2011. 90p. MSc Dissertation - Departamento de Psicologia, Pontifícia Universidade Católica do Rio de Janeiro.

This study has the goal of investigating, through the interview of patients with bulimia nervosa, how the family takes part of the treatment and the development of such eating disorder. In order to reach this goal, a qualitative research was organized, with six women diagnosed as such, aged from 19 to 35 years old and members of the middle and high economic classes of the Rio de Janeiro society. Initially, a theoretic study of the characteristics of bulimia nervosa and of the families with a member that suffered of such eating disorders was made, including the evolution of family treatment. This study served as a foundation for the analysis the interviews and, later, in the creation of six categories. Through the analysis of the interviews, there was evidence that most of them related directly their eating symptoms to family issues, pointing towards specific or recurring situations, in which they seeked shelter and support in food. Analyzing such reports, the conclusion was that the participation of the family is of extreme importance in the treatment of bulimia nervosa, in order for the issues related to the dysfunctional dynamic of this system to be treated and, this way, for the patient to present an improvement of their symptoms.

\section{Keywords}

Bulimia nervosa; eating disorders; family; psychotherapy. 


\section{Sumário}

$\begin{array}{ll}\text { 1. Introdução } & 11\end{array}$

2. A bulimia nervosa 14

2.1. Histórico e construção do conceito de bulimia nervosa 14

2.2. A importância da aparência na sociedade contemporânea 17

2.3. Etiologia dos transtornos alimentares 26

2.4. Critérios diagnósticos da bulimia nervosa 28

2.5. Os aspectos emocionais e psicológicos da bulimia nervosa 32

3. A família e o tratamento da bulimia nervosa 36

3.1. As características e a dinâmica das famílias de pacientes com transtornos alimentares 36

3.2. A evolução do tratamento familiar para a bulimia nervosa 47

4. A pesquisa $\quad 57$

4.1. Recrutamento e seleção dos participantes 57

4.2. A construção do roteiro para as entrevistas 58

4.3. As entrevistas 58

4.4. A transcrição das entrevistas $\quad 59$

4.5. A análise e discussão 59

5. Considerações finais 79

6. Referências bibliográficas 83

7. Anexos $\quad 89$

7.1. Anexo $1 \quad 89$

7.2. Anexo $2 \quad 90$ 
Falar em alimento é desde o princípio da vida falar em afeto. Falar em afeto é evidentemente falar em relação. Falar em relação é falar de pessoas com conflitos que intercambiam sentimentos, sensações, percepções e emoções.

Schomer (2003), O papel da família nos transtornos alimentares. 